\title{
Wenn Fuchs und Katze einander gute Nacht sagen könnten
}

\section{Peter Süsstrunk}

Med. pract., Mitglied der FMH

War man denn an diesem Spital so wenig seriös, dass man wegen sich eigentlich wenig geziemenden Lachens über die folgende Geschichte sich nicht mehr daran erinnerte, wer sie verbreitet hatte? Nächtlicherweile sei nämlich ein Fuchs in das am Waldrand gelegene Spital getrottet, leichtfüssig, um keinen Lärm zu machen, und habe dort - angeblich ausgerechnet im Gang, der zur «Abteilung für Psychosomatik» führt - eine Katze entdeckt, die offenbar auf demselben Weg wie er "zugelaufen" war. Dabei sei's zu folgender Unterhaltung zwischen dem grösseren und dem kleinen Tier gekommen:

Fuchs: Bist du hier Patientin? Du darfst nicht krank sein, denn das ist "gesellschaftlich untersagt", und wenn du etwas Verbotenes, wie es das Kranksein ist, tust, ziehe ich über dich her!

Katze: Spiel dich nicht auf, wie möchtest ausgerechnet du mir das Fell über die Ohren ziehen? Versuchs mal.

Fuchs: Nicht, solange du dir nicht erlaubst, krank zu sein. Katze: Und wenn ich doch krank wäre, als wäre das etwas Verbotenes?

Fuchs: Dann darfst du's dir nicht zugeben, sonst ...

Katze: Ja, ja.

Fuchs: ... schnappe ich dich mir.

Katze: Was ich mir zugebe und was nicht, geht dich gar nichts an.

Fuchs: Doch.

Katze: Ich möchte ja nicht unhöflich sein, aber, bist du krank?

Fuchs: Nein, aber mir ist wichtig, ob du eine Katze bist, die sich selbst gegenüber aufrichtig ist. Ich spreche nämlich nur mit ehrlichen Katzen.

Katze: Gerade eben hast du behauptet, man dürfe es sich, wenn man krank sei, nicht zugeben, wenn man sich dir nicht ausliefern möchte. Fällt dir nicht auf, dass du dir widersprichst?
Fuchs: Gut, aber angenommen, du wärst krank, würdest du's dir dann eingestehen? Wärst du dann wahrheitsliebend?

Katze: Wieso fragst du das?

Fuchs: Weil ... ich mich schämen würde, mich mit einer unehrlichen Katze abgegeben zu haben.

Katze: Bist du jetzt aufrichtig?

Fuchs: Ja, ja, ich bin eben so, dass mir wichtig ist, mit wem ich's bei einer Katze zu tun habe. Das ist eine ... Ehrensache, sonst ist man kein guter Fuchs. Das ist man sich schuldig! Wie würde ich jetzt vor mir dastehen, als derjenige, der sich dazu hergab, sich mit einer unredlichen Katze zu unterhalten?

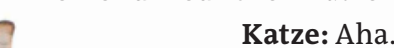

Fuchs: Was denn «Aha»?

Katze: Jetzt habe ich dich in der Hand: Wenn ich nicht redlich wäre, müsstest du dich zu Tode schämen, wegen Sich-Einlassens mit einer unredlichen Katze: Fuchs, gestorben wegen Scham, ehrenhalber! Fuchs: Du bist ja doch wahrheitsliebend.

Katze: Wieso denn das?

Fuchs: Du hast mich in die Falle gelockt und nützt es doch nicht aus.

Katze: Leben und leben Lassen. Wenn ich leben darf, sollst du's ebenso dürfen.

Fuchs: Danke, du hast mich gerettet! Tschüss, vielleicht werfe ich dir zur Anerkennung auch einmal einen «Stein in den Garten».

Katze: Ausser, ich wäre dann gerade krank, denn das ist ja bei euch Füchsen verboten - «gesellschaftlich». Fuchs: Du musst ja immer das letzte Wort haben. Katze: Und du immer das erste.

Bildnachweis

(c) Isselee | Dreamstime.com 